\title{
Relative Efficacy Of Ester Synthesis By Various Lipases In Microaqueous Media And The Effect Of Water On Reaction Progress
}

\author{
Purwiyatno Hariyadi ${ }^{1}{ }^{1}$ Kirk L. Parkin 21 \\ ${ }^{1}$ Department of Food Science Babcock Hall, 1605 Linden Drive University of Wisconsin \\ Madison, WI 53706 \\ ${ }^{2}$ Corresponding author: Ph: (608) 263-2011; FAX (608) 262-6872; E-mail: \\ klparkin@facstaff.wisc.edu.
}

${ }^{1}$ Present address: Department of Food Technology and Human Nutrition Faculty of Agricultural Technology Bogor Agricultural University P.O. Box 220, Bogor 16002, Indonesia

Copyright 1997 Food \& Nutrition Press, Inc.

\begin{abstract}
Ten commercial sources of lipases were evaluated for comparative hydrolytic (in an aqueous emulsion) and ester synthesis (in microaqueous media) activities. There was little relationship between these activities for the lipases evaluated. An immobilized Rhizomucor miehei lipase had the greatest ester synthesis activity but had comparatively limited hydrolytic activity. For the five most effective ester synthesizing lipases, each had a characteristic optimum water content for maximum initial reaction rates. However, this optimum water content was greater than that associated with maximum reaction yield of ester formation, indicating the need for unique and differential moisture control during the progress of reaction to obtain maximum process efficiency.
\end{abstract}

Received for Publication September 24, 1996; Accepted for Publication December 5, 1996 